\title{
Modelling the transformations and sequestration of soil organic matter in two contrasting ecosystems of the Andes
}

\author{
M. PAnsu ${ }^{\mathrm{a}}$, L. SARmiento $^{\mathrm{b}}, \mathrm{K} \cdot$ MetselaAr $^{\mathrm{c}}$, D. Hervé $^{\mathrm{a}} \&$ P. Bottner $^{\mathrm{d}}$ \\ a IRD, BP 64501, 34394 Montpellier Cedex 05, France, ${ }^{\mathrm{b}}$ ICAE, Facultad de Ciencias, Universidad de los Andes, Mérida 5101, \\ Venezuela, ' Soil Physics, Ecohydrology and Groundwater Management, Wageningen University, PO Box 9101,6700 HB Wageningen, \\ The Netherlands, and ${ }^{\mathrm{d}}$ CEFE-CNRS 1919, Route de Mende, 34293 Montpellier Cedex 05, France
}

\begin{abstract}
Summary
The mechanisms linking soil respiration to climate and soil physical properties are important for modelling transformation and sequestration of $\mathrm{C}$ and $\mathrm{N}$ in the soil. We investigated them by incubating ${ }^{14} \mathrm{C}$ and ${ }^{15} \mathrm{~N}$ labelled straw in soils of the dry puna (Bolivian altiplano, semi-arid shrubland at $3789 \mathrm{~m}$ above sea level) and the humid paramo (Venezuelan tropical alpine vegetation at $3400 \mathrm{~m}$ ). These two ecosystems of the high Andes are comparable in terms of altitude, mean temperature and land use, but are very different regarding organic matter content, rainfall patterns and soil physical properties. Total ${ }^{14} \mathrm{C}$ and ${ }^{15} \mathrm{~N}$, microbial-biomass ${ }^{14} \mathrm{C}$ and ${ }^{15} \mathrm{~N}$, soil moisture and meteorological data were recorded over 2 years. Daily soil moisture was predicted from a water balance model. The data from the paramo site were used to calibrate MOMOS-6, a model of organic matter decomposition based on microbial activity and requiring only kinetic constant parameters to describe: (i) inputs to microbial biomass from plant debris and microbial metabolites, and (ii) losses from the biomass by mortality and respiration (respiration coefficient and microbial metabolic quotient $q \mathrm{CO}_{2}$ ). The simulated $q \mathrm{CO}_{2}{ }^{-14} \mathrm{C}$ agrees well with $q \mathrm{CO}_{2}-{ }^{14} \mathrm{C}$ and $q \mathrm{CO}_{2}$ measured at the calibration site and with published data. To apply MOMOS-6 to the puna site, only the respiration coefficient of the biomass was re-estimated. The dynamics of ${ }^{14} \mathrm{C}$ and ${ }^{15} \mathrm{~N}$ were very different in the two systems. In the puna, the transformation processes stop during the long dry periods, though total annual mineralization is greater than in the paramo. The change in the value of the respiration coefficient enables us to predict that the amount of $\mathrm{C}$ and $\mathrm{N}$ sequestered in the stable humus is greater in the paramo than in the puna. The data in this paper can be used to estimate values of the respiration coefficient so that MOMOS- 6 can be applied to other systems.
\end{abstract}

\section{Introduction}

Modelling transfers of $\mathrm{C}$ and $\mathrm{N}$ through the compartments of soil organic matter requires understanding of the dynamics of soil microbial biomass. The quantification of this pool proposed by Jenkinson \& Powlson (1976) and the quantification of its activity with the microbial metabolic quotient, $q \mathrm{CO}_{2}$, explored by Anderson \& Domsch (1993) were essential steps for modelling. At present, many concepts are available, considering the microbial biomass as a single compartment, or two or more compartments, including the biomass in labile compartment(s), or not regarding the biomass as a state variable, but as a rate-controlling factor. Weather and soil properties are often used to explain year-to-year and site-to-site differences. Most models use similar response functions for temperature

Correspondence: M. Pansu. E-mail: pansu@mpl.ird.fr

Received 14 April 2005; revised version accepted 27 July 2006 and moisture, but different options are suggested to model the effect of soil properties. Soil texture is generally considered to be an essential factor in controlling the dynamics of soil organic matter and has been related to:

1 the decay rate of the organic compartments (Van Veen et al., 1985; Hansen et al., 1991; Molina et al., 1998);

2 the flow fractionation (or efficiency factors) between organic compartments (Jenkinson, 1990);

3 the growth rate of decomposers (Bosatta \& Ågren, 1997);

4 the relations between active and stabilized organic matter (Parton et al., 1987);

5 the partitioning of the organic matter within protected and non-protected compartments (Verberne et al., 1990);

6 the processes of adsorption and desorption of organic compounds in the aggregates (Hassink \& Whitmore, 1997); and

7 the quantity of decomposing organisms (Müller \& Höper, 2004). 
To gain further insight into the factors controlling microbial respiration and the mechanisms that stabilize organic matter we modelled results from a ${ }^{14} \mathrm{C}$ and ${ }^{15} \mathrm{~N}$ labelling experiment carried out in the field simultaneously at two sites with similar characteristics (altitude, mean temperature, and long fallow cropping system), but with soils differing in content of organic matter and physical properties, and with different rainfall. The MOMOS-6 model, selected from five reasonable models (Pansu et al., 2004), was used to simulate the mineralization and transfers of ${ }^{14} \mathrm{C}$ and ${ }^{15} \mathrm{~N}$. Like the approach described by Saggar et al. (1996) and Schimel \& Weintraub (2003), MOMOS-6 is centred on the microbial biomass compartment: the microbial inputs are the outputs of the other compartments, and the microbial output is defined by the respiration quotient (the only $\mathrm{CO}_{2}$ output) and the mortality rate. Our general aim was to understand how the physical and chemical properties of the soil control the respiration processes: does this model allow us to formulate and quantify a specific mechanism to explain the different behaviour of the two soils with respect to $\mathrm{C}$ and $\mathrm{N}$ storage?

\section{Methods}

The experimental sites

Experiments with identical designs were laid out at Gavidia $\left(8^{\circ} 40^{\prime} \mathrm{N}, 70^{\circ} 55^{\prime} \mathrm{W}\right)$ in the humid Venezuelan paramo and at
Patacamaya $\left(17^{\circ} 15^{\prime} \mathrm{S}, 67^{\circ} 57^{\prime} \mathrm{W}\right)$ in the dry Bolivian puna (Table 1). At each site, the experiment was set up in: (i) a 2year-old fallow plot (referred to as 'young' in Table 2, four replicates), and (ii) a 7-year-old fallow plot (referred to as 'old' in Table 2, four replicates). The vegetation is dominated by the perennial herb Rumex acetosella in the young paramo and by Chondrosum simplex and Erodium cicutarium in the young puna. It is dominated by the shrub Baccharis prunifolia and the giant rosette Espeletia schultzii in the old paramo plots (1-1.5 $\mathrm{m}$ tall) and by the shrubs Baccharis incarum and Parastrephia lepidophylla in the old puna plots (less than $1 \mathrm{~m}$ tall). Table 2 presents soil cover by natural vegetation. The sites, representative of two major tropical Andean zones of the upper altitude belt of cultivation, differ markedly in terms of organic matter content, soil moisture content (Figure 3) and textural characteristics.

\section{Field incubation}

Spring wheat (Florence Aurore) was grown from seed to grain formation in a labelling chamber with controlled conditions of ${ }^{14} \mathrm{CO}_{2}$ atmosphere $\left(0.03{ }^{14} \mathrm{C} / 100{ }^{12} \mathrm{C}, 0.86 \mathrm{kBq} \mathrm{mg}{ }^{-1} \mathrm{C}\right)$, temperature and radiation. The plants, cultivated in pure sand, were periodically flooded with a complete nutrient solution containing $\mathrm{Ca}\left({ }^{15} \mathrm{NO}_{3}\right)_{2}\left(10{ }^{15} \mathrm{~N} / 100{ }^{14} \mathrm{~N}\right)$ as the sole source of N. At harvest, the wheat was dried at $40^{\circ} \mathrm{C}$. The stems and leaves were used in the experiment. They were milled to yield

Table 1 Main characteristics of the experimental sites; for a more detailed description see also Sarmiento (1995) for the paramo and Hervé (1994) for the puna

\begin{tabular}{|c|c|c|}
\hline Sites & Paramo Gavidia (Venezuela) & Puna Patacamaya (Bolivia) \\
\hline Coordinates & $8^{\circ} 40^{\prime} \mathrm{N} ; 70^{\circ} 55^{\prime} \mathrm{W}$ & $17^{\circ} 15^{\prime} \mathrm{S} ; 67^{\circ} 57^{\prime} \mathrm{W}$ \\
\hline Cropping system & $\begin{array}{l}\text { Long grazing fallow periods } \\
\text { ( } 7-10 \text { years) alternating with short } \\
\text { ( } 2 \text { years) potatoes and barley }\end{array}$ & $\begin{array}{l}\text { Long grazing fallow periods } \\
\text { ( } 7-8 \text { years) alternating with short } \\
\text { ( } 2-3 \text { years) potatoes, barley or quinoa }\end{array}$ \\
\hline $\mathrm{T}$ mean (average) $/{ }^{\circ} \mathrm{C}$ & 8.5 & 8.7 \\
\hline T minimum (average) $/{ }^{\circ} \mathrm{C}$ & 5 & 0.2 \\
\hline $\mathrm{T}$ maximum (average) $/{ }^{\circ} \mathrm{C}$ & 9 & 17.2 \\
\hline Soil name (WRB) & Regosol & Arenosol \\
\hline Soil depth/cm & 70 & 30 \\
\hline Volumetric stone content ( $0-10 \mathrm{~cm}$ layer $)$ & $0.26 \pm 0.04^{\mathrm{a}}$ & $0.20 \pm 0.07^{\mathrm{a}}$ \\
\hline Clay $/ \%$ & $15 \pm 2.5$ & $6 \pm 0.5$ \\
\hline $\mathrm{pH}\left(\mathrm{H}_{2} \mathrm{O}\right)$ & $4.5 \pm 0.1$ & $6.6 \pm 0.2$ \\
\hline $\mathrm{C} / \%$ & $9.9 \pm 0.6$ & $0.5 \pm 0.1$ \\
\hline $\mathrm{N} / \%$ & $0.65 \pm 0.08$ & $0.06 \pm 0.02$ \\
\hline $\mathrm{C}: \mathrm{N}$ ratio & $15.3 \pm 1.9$ & $7.6 \pm 2.5$ \\
\hline MCFC (volumetric moisture content at field capacity) & $0.52 \pm 0.02$ & $0.35 \pm 0.02$ \\
\hline MCWP (volumetric moisture content at wilting point) & $0.28 \pm 0.01$ & $0.06 \pm 0.01$ \\
\hline
\end{tabular}

${ }^{\mathrm{a}}$ Mean \pm standard error $(n=4)$. 
Table 2 Treatments and characteristics of the plots

\begin{tabular}{|c|c|c|c|c|}
\hline & \multicolumn{4}{|c|}{ Sites } \\
\hline & Young fallow & Old fallow & Young fallow & Old fallow \\
\hline Fallow age/year & 2 & 7 & 2 & 7 \\
\hline Soil cover by natural vegetation/surface ratio & 0.85 & 0.9 & 0.2 & 0.4 \\
\hline \multicolumn{5}{|l|}{ Soil native organic matter } \\
\hline Soil N $/ \%^{a}$ & $0.55 \pm 0.03$ & $0.56 \pm 0.01$ & $0.08 \pm 0.002$ & $0.09 \pm 0.004$ \\
\hline Soil C/N $(n=8)$ & 17.1 & 15.8 & 5.6 & 6.3 \\
\hline Duration of the experiment & \multicolumn{2}{|c|}{ from $13 / 11 / 1998$ to $10 / 11 / 2000$} & \multicolumn{2}{|c|}{ from $29 / 11 / 1998$ to $27 / 11 / 2000$} \\
\hline Dry soil in each $\mathrm{bag} / \mathrm{g}$ & \multicolumn{2}{|c|}{150} & \multicolumn{2}{|l|}{150} \\
\hline Weight of straw added to each bag/g straw per sample & \multicolumn{2}{|l|}{3.26} & \multicolumn{2}{|l|}{0.347} \\
\hline Smallest measured ${ }^{15} \mathrm{~N}$ enrichment $(n=8)^{\mathrm{a}} / \%$ & $0.369 \pm 0.003$ & $0.354 \pm 0.004$ & $0.212 \pm 0.009$ & $0.204 \pm 0.007$ \\
\hline Soil natural ${ }^{15} \mathrm{~N}$ isotopic ratio $(n=12)^{\mathrm{a}} / \%$ & $0.367 \pm 0.0001$ & $0.367 \pm 0.0001$ & $0.373 \pm 0.0003$ & $0.371 \pm 0.0003$ \\
\hline
\end{tabular}

${ }^{\mathrm{a}}$ Mean \pm standard error.

2-7 $\mathrm{mm}$ long pieces. The characteristics of the dry plant material were: $\mathrm{C}=43 \%, \mathrm{~N}=1.60 \%,{ }^{15} \mathrm{~N}$ isotopic enrichment $=$ $9.88 \%,{ }^{14} \mathrm{C}$ activity $=598 \mathrm{~Bq} \mathrm{mg}^{-1} \mathrm{C}$, soluble compounds $=$ $36.1 \%$, hemicelluloses $=25.2 \%$, cellulose $=26 \%$, lignin $=3 \%$, and ash $=9.4 \%$ (Van Soest et al., 1991).

At each site, the labelled straw was incubated in soil from both young and old fallow plots as follows. Soil from the $5-10 \mathrm{~cm}$ layer of each plot was collected, homogenized, air-dried and used to fill 40 bags ( $150 \mathrm{~g}$ of soil per bag) made of $10 \mathrm{~cm} \times 8 \mathrm{~cm}$ sealed polyester with a $1-\mathrm{mm}$ mesh on the upper side and $0.5 \mathrm{~mm}$ on the lower side. Labelled straw was added homogeneously to each bag (Table 2). The bags were placed horizontally in the $5-10 \mathrm{~cm}$ layer and covered with soil from the $0-5 \mathrm{~cm}$ layer. At installation the $0-10 \mathrm{~cm}$ layer was brought to field capacity with rainwater. The experiment lasted for 2 years (Table 2), during which four bags from each treatment were randomly taken on 10 occasions (including the initial sampling).

\section{Analysis}

At each sampling date, the four wet samples were homogenized and analysed as shown in Table 2. Three 5-g subsamples were used for moisture measurements, and for the remainder, total ${ }^{14} \mathrm{C}$ and total ${ }^{15} \mathrm{~N}$ and microbial biomass- ${ }^{14} \mathrm{C}$ and $-{ }^{15} \mathrm{~N}$ were measured. Microbial biomass was measured by the fumigation-extraction method as described in Pansu et al. (2004). We used 20-g subsamples for chloroform fumigation and unfumigated control, and $150 \mathrm{ml}$ of $0.5 \mathrm{M} \mathrm{K}_{2} \mathrm{SO}_{4}$ solution as extracting reagent. We measured ${ }^{14} \mathrm{C}$ in the fumigated and control extracts (corrective factor $0.45 ; 2 \times 4$ replicates) by liquid scin- tillation counting (Tricarb 1500, Packard, Downers Grove, Illinois, USA) and ${ }^{15} \mathrm{~N}$ (corrective factor $0.54 ; 1 \times 4$ replicates) by Kjeldahl distillation, followed by mass spectrometry (Finnigan delta S, Rodano, Milano, Italy). We measured total ${ }^{14} \mathrm{C}$ using a Carmograph $12 \mathrm{~A}$ (Wösthoff, Bochum, Germany) and liquid scintillation counting (Tricarb 1500 modified according to Bottner $\&$ Warembourg, 1976; $8 \times 4$ replicates). Total ${ }^{15} \mathrm{~N}$ was measured with a coupled $\mathrm{CHN} /$ Mass spectrometer (SCA-CNRS, Solaize, France; $2 \times 4$ replicates). The ${ }^{14} \mathrm{C}$ and ${ }^{15} \mathrm{~N}$ of the plant material were analysed by the same procedure as for soil samples.

Daily precipitation, maximum and minimum air temperature, and total radiation were recorded automatically by a weather station (Campbell, Loughborough, UK) throughout the experiment.

\section{The decomposition model}

We distinguished five compartments of soil organic matter in the MOMOS-6 model (Figure 1):

1 labile (VL) plant materials from necromass (NC);

2 stable (VS) plant materials from necromass $(\mathrm{VL}+\mathrm{VS}=\mathrm{NC})$;

3 microbial biomass (MB);

4 labile humus (HL); and

5 stable humus (HS).

All flows pass through the MB compartment. The inputs to the microbial compartment are the flows from the plant material compartments VL and VS, and those from the humus compartments HL and HS. The outputs are microbial respiration (calculated from $q \mathrm{CO}_{2}$ ) and microbial mortality ( $k_{\mathrm{MB}}$ mortality rate). Part of the model is similar to that used by Franko et al. 


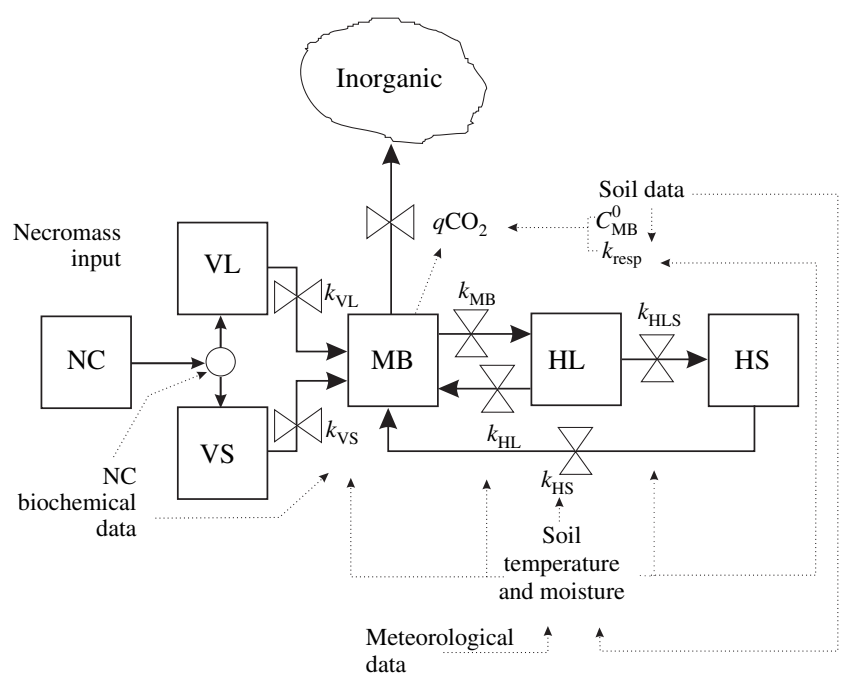

Figure 1 Flow chart of the MOMOS-6 model: NC is necromass input, VL is labile $\mathrm{NC}$ fraction, VS is stable $\mathrm{NC}$ fraction, $\mathrm{MB}$ is microbial biomass, $\mathrm{HL}$ is labile humus, HS is stable humus; $q \mathrm{CO}_{2}$ is the metabolic quotient of $\mathrm{MB}$; $k_{\text {resp }}$ is the respiration rate of $\mathrm{MB}$; $C_{\mathrm{MB}}^{0}$ is the C content of $\mathrm{MB}$ at steady state; $k_{\mathrm{MB}}$ is the mortality rate of $\mathrm{MB} ; k_{\mathrm{VL}}, k_{\mathrm{VS}}, k_{\mathrm{HL}}, k_{\mathrm{HS}}$ are the ingestion rates by $\mathrm{MB}$ of $\mathrm{VL}, \mathrm{VS}$, $\mathrm{HL}$ and HS, respectively; $k_{\mathrm{HLS}}$ is the rate of stabilization to HS from HL.

(1995) in the CANDY model, and by Saggar et al. (1996) to calculate ${ }^{14} \mathrm{C}$ turnover and residence time in soils. The MOMOS-6 model and these models differ in the following aspects:

1 the necromass input (NC) is partitioned over VL and VS on the basis of the $\mathrm{NC}$ biochemical characteristics, with equations proposed by Thuriès et al. (2002) giving a stable fraction $f_{\mathrm{s}}$ of $0.107 \mathrm{NC}$ for this material;

2 the dynamics of the $\mathrm{CO}_{2}$ output of the whole system is driven by the microbial respiration (see Equations 5 and 6 below);

3 the flow from VL and VS to microbial biomass is not partitioned as in the CANDY model; instead all NC is used quickly (VL) or slowly (VS) as substrate by the biomass;

4 a stable humus compartment (HS) is included, which results from the slow stabilization of HL and supplies maintenance energy to the dormant biomass when the labile compartments are exhausted; and

5 the MOMOS-6 model is parameterized only by seven firstorder kinetic constants (dimension day ${ }^{-1}$ ) and no partitioning coefficients of flows between compartments are used.

To describe this field labelling experiment, the general equation of the model is

$$
\dot{\mathbf{x}}=f(T) f(\theta) \mathbf{A} \mathbf{x},
$$

where $f(T)$ is the exponential function with $Q_{10}=2$ and a reference temperature $=20^{\circ} \mathrm{C}$ (Kätterer et al., 1998), with the soil temperature $T$ (5-10 cm layer) set equal to air temperature, $f(\theta)$ is a soil moisture function (SAHEL model predictions, Penning de Vries et al., 1989) related to field capacity (Andrén \& Paustian, 1987), $\mathbf{x}$ is the vector of the state variables (carbon contents of compartments), $\dot{\mathbf{x}}$ is the corresponding vector of the rate variables and $\mathbf{A}$ is the parameter matrix of the model:

$$
\mathbf{A}=\left[\begin{array}{lllll}
-k_{\mathrm{VL}} & 0 & 0 & 0 & 0 \\
0 & -k_{\mathrm{VS}} & 0 & 0 & 0 \\
k_{\mathrm{VL}} & k_{\mathrm{VS}} & -\left(q \mathrm{CO}_{2}+k_{\mathrm{MB}}\right) & k_{\mathrm{HL}} & k_{\mathrm{HS}} \\
0 & 0 & k_{\mathrm{MB}} & -\left(k_{\mathrm{HL}}+k_{\mathrm{HLS}}\right) & 0 \\
0 & 0 & 0 & k_{\mathrm{HLS}} & -k_{\mathrm{HS}}
\end{array}\right]
$$

and

$$
\mathbf{x}=\left[\begin{array}{l}
x_{\mathrm{VL}} \\
x_{\mathrm{VS}} \\
x_{\mathrm{MB}} \\
x_{\mathrm{HL}} \\
x_{\mathrm{HS}}
\end{array}\right]
$$

If $C_{0}$ is the amount of initially added ${ }^{14} \mathrm{C}$, and $f_{\mathrm{S}}$ its stable fraction, the initial conditions for the ${ }^{14} \mathrm{C}$ experiment are given by

$$
\begin{aligned}
x_{\mathrm{VL}}(0) & =\left(1-f_{\mathrm{S}}\right) C_{0}, \\
x_{\mathrm{VS}}(0) & =f_{\mathrm{S}} C_{0}, \\
x_{\mathrm{MB}}(0) & =0, \\
x_{\mathrm{HL}}(0) & =0, \\
x_{\mathrm{HS}}(0) & =0 .
\end{aligned}
$$

At each incubation time, the total ${ }^{14} \mathrm{C}$ decrease ( $c$ from the five compartments) is

$$
\dot{c}=\dot{x}_{\mathrm{VL}}+\dot{x}_{\mathrm{VS}}+\dot{x}_{\mathrm{MB}}+\dot{x}_{\mathrm{HL}}+\dot{x}_{\mathrm{HS}},
$$

which gives

$$
\dot{c}=-q \mathrm{CO}_{2} \mathrm{x}_{\mathrm{MB}},
$$

where $q \mathrm{CO}_{2}$ is the metabolic quotient of the microbial biomass. Another condition is necessary: $q \mathrm{CO}_{2}$ has to be controlled by the size of the microbial compartment. The $q \mathrm{CO}_{2}$ value has to increase when the carbon of the microbial biomass grows (particularly in response to an important supply from VL), and to decrease when $x_{\mathrm{MB}}$ decreases and microorganisms become dormant. In order to generalize the application of MOMOS-6 to various situations, Pansu et al. (2004) proposed a respiration coefficient, $k_{\text {resp }}$ (dimension day ${ }^{-1}$ ), scaled by the biomass at steady state, $C_{\mathrm{MB}}^{0}$, i.e. measured on bare soil unsupplied with recent input of substrate. In this experiment, $C_{\mathrm{MB}}^{0}$ was measured (paramo) or estimated (puna) at the last sampling time. Thus $q \mathrm{CO}_{2}$ is defined by

$$
q \mathrm{CO}_{2}=k_{\text {resp }} \frac{x_{\mathrm{MB}}}{C_{\mathrm{MB}}^{0}} .
$$

We derived the nitrogen model from the carbon model by dividing the $\mathrm{C}$ content of each organic compartment by its $\mathrm{C}: \mathrm{N}$ ratio 
(Pansu et al., 2004). The Powell optimization method was used to estimate the parameter values (Table 3).

\section{Results}

\section{Weather data}

Both sites above $3400 \mathrm{~m}$ are cold (Figure 2), despite their latitudes near the equator (Table 1). The daily mean temperature of the paramo was fairly stable during the two experimental years (daily range between 8 and $11^{\circ} \mathrm{C}$, with about $25 \%$ of the values between 6 and $12^{\circ} \mathrm{C}$ ). Mean daily air temperature in the puna has a more pronounced seasonality and the amplitudes are larger (daily range between 8 and $14^{\circ} \mathrm{C}$ in summer and between 2 and $6^{\circ} \mathrm{C}$ in winter) with occasional frosts (Figure 2).

The longer wet seasons, greater rainfall and water-holding capacity of the soil (Table 1) result in greater water storage in the wet paramo than in the dry puna. The SAHEL model prediction of soil moisture regime accorded well with the measurements on each sampling occasion (Figure 3). The $5-10 \mathrm{~cm}$ soil layer holds $0.3-0.5 \mathrm{~mm}$ water $\mathrm{mm}^{-1}$ in the paramo and only $0.01-0.3 \mathrm{~mm}$ water $\mathrm{mm}^{-1}$ in the puna. In the paramo, the combined reduction factor, $f(T) f(\theta)$ (Figure 4), varied between 0.2 and 0.3 during the dry season, and between 0.3 and 0.5 during the long wet season. In the puna, a value of 0.5 was reached only after rainstorms in the southern summer. During the long dry seasons of the puna, the decomposition processes are slow: $f(T) f(\theta) \approx 0.01$ (Figure 4) when moisture storage was about $0.01 \mathrm{~mm}$ water $\mathrm{mm}^{-1}$ (Figure 3). Thus, the weather for decomposition was less favourable in the puna than in the paramo.

\section{Model calibration and microbial respiration}

The $C_{\mathrm{MB}}^{0}$ was set to the value of $\mathrm{MB}$ at the last sampling time estimated from Equation (7) in the dry puna. The model was first calibrated on the more complete data of the paramo site

Table 3 The parameters of the MOMOS-6 model at the two sites (all $k$ are first-order kinetic constants in day ${ }^{-1}$ unit)

\begin{tabular}{llll}
\hline Symbol & \multicolumn{1}{c}{ Meaning } & Paramo & Puna \\
\hline$k_{\mathrm{VL}}$ & Ingestion rate of $\mathrm{VL}^{\mathrm{a}}$ by $\mathrm{MB}^{\mathrm{b}}$ & 0.6 & 0.6 \\
$k_{\mathrm{VS}}$ & Ingestion rate of $\mathrm{VS}^{\mathrm{c}}$ by MB & 0.003 & 0.003 \\
$k_{\mathrm{HL}}$ & Ingestion rate of $\mathrm{HL}^{\mathrm{d}}$ by MB & 0.05 & 0.05 \\
$k_{\mathrm{HS}}$ & Ingestion rate of $\mathrm{HS}^{\mathrm{e}}$ by MB & 0.00005 & 0.00005 \\
$k_{\mathrm{HLS}}$ & Stabilization rate of $\mathrm{HL}$ to $\mathrm{HS}$ & 0.0003 & 0.0003 \\
$k_{\mathrm{MB}}$ & Mortality rate of $\mathrm{MB}$ & 0.45 & 0.45 \\
$k_{\mathrm{resp}}$ & Respiration rate of $\mathrm{MB}$ & 0.03 & 0.084 \\
$C_{\mathrm{MB}}^{0}$ & Equilibrium value of $\mathrm{MB}^{14}{ }^{14} / \mathrm{g} \mathrm{kg}^{-1}$ & 0.15 & 0.015 \\
\hline
\end{tabular}

${ }^{\mathrm{a}}$ Labile organic material of necromass.

${ }^{\mathrm{b}}$ Microbial biomass.

'Stable organic material of necromass.

${ }^{\mathrm{d}}$ Labile humified material.

${ }^{\mathrm{e}}$ Stable humified material.
(Pansu et al., 2004) to give the parameter values listed in Table 3. The model was then used to predict the puna data, but re-calibration was necessary. We obtained the best fit by optimizing $k_{\text {resp. }}$. All other values estimated with the paramo data were retained (Table 3 ). After this re-calibration, the two sites differed only in terms of the respiration coefficient $\left(k_{\text {resp }}\right)$ and the equilibrium value of the $\mathrm{MB}$ ( $C_{\mathrm{MB}}^{0}$, Table 3). At the dry puna site the value of $k_{\text {resp }}$ was estimated to be almost three times as large as that in the wet paramo. The effect is a large simulated difference in the metabolic quotient $q \mathrm{CO}_{2^{-}}{ }^{14} \mathrm{C}$ between the two ecosystems (Figure 5). After a large initial peak in both systems, the $q \mathrm{CO}_{2^{-}}{ }^{14} \mathrm{C}$ in the wet paramo varies between 15 and $30 \mathrm{mg}\left(\mathrm{CO}_{2^{-}}{ }^{14} \mathrm{C}\right) \mathrm{g}^{-1}$ (microbial- ${ }^{14} \mathrm{C}$ ) day $^{-1}$ during the first year, and between 10 and 20 during the second year. The $q \mathrm{CO}_{2}{ }^{14} \mathrm{C}$ curve in the dry puna is very different from that of the paramo as it contains both periods where the respiration is almost halted by the dry and cold weather $(f(T) f(\theta) \approx 0$, Figure 4), and there are large fluctuations (between 10 and $65 \mathrm{mg}\left(\mathrm{CO}_{2}-{ }^{14} \mathrm{C}\right.$ ) $\mathrm{g}^{-1}$ (microbial- ${ }^{14} \mathrm{C}$ ) day $^{-1}$ in the first 6 months, and between 2 and 55 after that). These large fluctuations coincide with rain events during the wet season. As soon as the moisture conditions are favourable for microorganisms, the metabolic quotient increases more in the puna than in the paramo, as a result of the differences in $k_{\text {resp. }}$.

\section{${ }^{14} \mathrm{C}$ transformations}

The measured and simulated values (from the parameter values in Table 3) of total- ${ }^{14} \mathrm{C}$ and ${ }^{14} \mathrm{C}$ in $\mathrm{HL}$ and $(\mathrm{VL}+\mathrm{VS})$ compartments are displayed in Figure 6. The measured differences between the young and old fallow plots were not significant at any sampling time, except during the first year of incubation in the puna. Bottner et al. (2006) discuss the effect of fallow age. The total ${ }^{14} \mathrm{C}$ dynamics were very different in the two ecosystems. In the dry puna, $66 \%$ of the initially added ${ }^{14} \mathrm{C}$ was quickly mineralized during the first wet season (the first 120 days). Afterwards, mineralization was almost at a standstill until the end of the dry season (at day 400 ), then $73 \%$ of the added ${ }^{14} \mathrm{C}$ was mineralized after the second wet season (at day 500 ), and $75 \%$ at day 690 after the first rain that followed the last long dry period. In the wet paramo, only $42 \%$ of the added ${ }^{14} \mathrm{C}$ was mineralized during the fast initial phase of the process, then mineralization progressed more slowly, but steadily, until about $65 \%$ of the added ${ }^{14} \mathrm{C}$ was mineralized after 1 year, and $75 \%$ after 2 years.

MOMOS- 6 simulated large values of microbial- ${ }^{14} \mathrm{C}$ at the beginning of the experiments for both ecosystems (Figure 7). The values decreased quickly during the first few days and more slowly later on. In the wet paramo, microbial- ${ }^{14} \mathrm{C}$ accounted for $4 \%$ of the added ${ }^{14} \mathrm{C}$ after 1 month, $2.5 \%$ after 1 year and $1.8 \%$ after 2 years, in accord with the measured data. In the dry puna, the simulated microbial- $-{ }^{14} \mathrm{C}$ accounted for $3.5 \%$ of the added ${ }^{14} \mathrm{C}$ after 2 months of incubation, $2 \%$ 

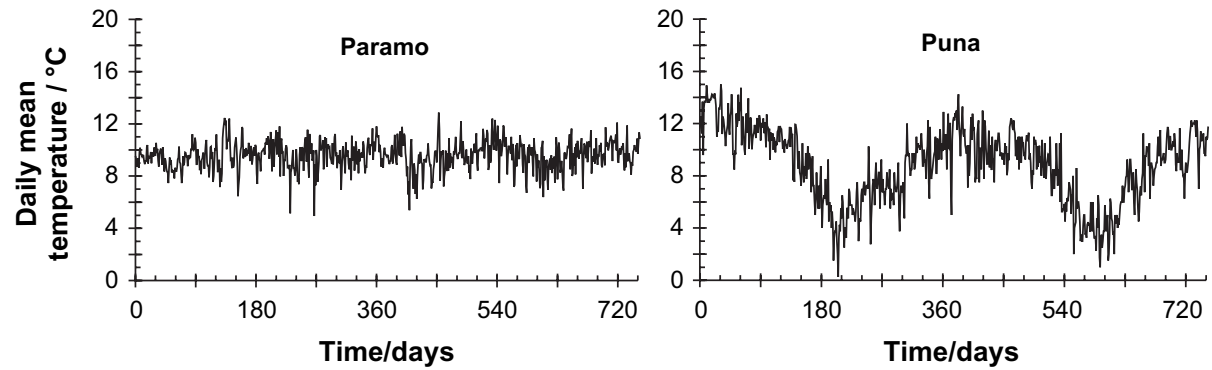

Figure 2 Measured daily mean air temperature at the two sites. For time axis, day 0 is 13 November 1998. after 6 months and $1.5 \%$ after 2 years. In the puna, there were no measured MB data, but the puna simulations were similar to a hypothetical microbial- ${ }^{14} \mathrm{C}$ calculated assuming equal microbial- ${ }^{14} \mathrm{C}$ :total- ${ }^{14} \mathrm{C}$ ratios at the two sites:

$$
\text { microbial- }{ }^{14} \mathrm{C}_{\text {puna }}=\text { microbial- }{ }^{14} \mathrm{C}_{\text {paramo }} \frac{\text { total }{ }^{14} \mathrm{C}_{\text {Puna }}}{\text { total }{ }^{14} \mathrm{C}_{\text {Paramo }}} .
$$

At both sites, the model predicted that only $10 \%$ of the added ${ }^{14} \mathrm{C}$ remained in the plant necromass $(\mathrm{VL}+\mathrm{VS})$ after 2 months of incubation (Figure 6). Then the ${ }^{14} \mathrm{C}$ of the VS decreased faster in the paramo $\left(4 \%\right.$ of the added ${ }^{14} \mathrm{C}$ after 2 years) than in the puna (9\% after 2 years). The transfers of ${ }^{14} \mathrm{C}$ through the HL compartment were greater in the paramo than in the puna. In the paramo MOMOS- 6 simulated $40 \%$ of the

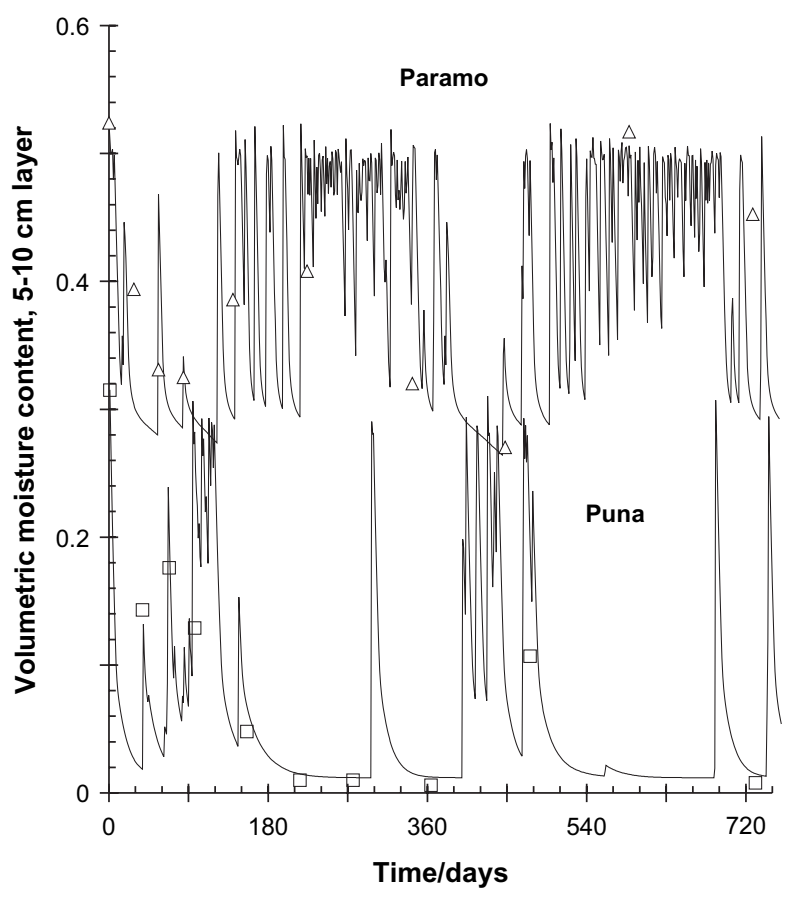

Figure 3 Volumetric soil moisture content in the $5-10 \mathrm{~cm}$ soil layers of the two sites: lines are predictions of the SAHEL model, symbols represent data measured in soil bags. For time axis, day 0 is 13 November 1998. added ${ }^{14} \mathrm{C}$ in the $\mathrm{HL}$ after 1 month of incubation, $24 \%$ after 1 year and $15 \%$ after 2 years. In the puna, the values were: $25 \%$ after 2 months, $20 \%$ after 1 year and $15 \%$ after 2 years. The predicted ${ }^{14} \mathrm{C}$ sequestration in the stable humus compartment (HS, Figure 7) in the paramo was five times that of the puna HS $(2 \%$ in the paramo and $0.4 \%$ in the puna of added ${ }^{14} \mathrm{C}$, after 2 years of incubation).

\section{${ }^{15} \mathrm{~N}$ transformations}

The measured (young and old fallow plots) and predicted values of total $-{ }^{15} \mathrm{~N}$ and ${ }^{15} \mathrm{~N}$ in $\mathrm{NC}(\mathrm{VL}+\mathrm{VL}), \mathrm{HL}$ and inorganic compartments are presented in Figure 8. The changes in ${ }^{15} \mathrm{~N}$ were very different at the two sites. The total ${ }^{15} \mathrm{~N}$ added in the puna was mineralized faster than in the paramo. In the puna, $30 \%$ of the added ${ }^{15} \mathrm{~N}$ was mineralized in the first 2 weeks of incubation and $45 \%$ in the first 4 months. Mineralization almost halted during the dry periods and was weakly reactivated during the rainy periods. At the end of incubation, $55 \%$ of added ${ }^{15} \mathrm{~N}$ was mineralized. In the paramo, the mineralization of the total ${ }^{15} \mathrm{~N}$ accounted for only $10 \%$ of the added ${ }^{15} \mathrm{~N}$ during the first month, after which the mineralization was slower and constant, and amounted to about $30 \%$ and $35 \%$ of the added ${ }^{15} \mathrm{~N}$ after 1 and 2 years of incubation, respectively. In the first 4 months, the puna produced the same proportion of inorganic- ${ }^{15} \mathrm{~N}$ (in percentage of added ${ }^{15} \mathrm{~N}$ ) as the paramo in 2 years.

The predicted amount of ${ }^{15} \mathrm{~N}$ remaining in the undecomposed plant material (VL + VS) was approximately the same at the two sites. In the puna, during the first 2 months of incubation, the proportion of added- ${ }^{15} \mathrm{~N}$ stored in MB (Figure 9) was greater, but decreased more quickly than in the paramo, rapidly reaching a smaller value. The proportion of ${ }^{15} \mathrm{~N}$ stored in the labile microbial metabolites (HL, Figure 8) was also much less in the puna (months 2-10, 42\%; 1 year, $40 \%$; 2 years, 33\%) than in the paramo (months $1-8,68 \%$ of added- ${ }^{15} \mathrm{~N}$; 1 year, $55 \%$; 2 years, $41 \%$ ). As for ${ }^{14} \mathrm{C}$, the predicted amount of ${ }^{15} \mathrm{~N}$ stabilized in the paramo HS (Figure 9) was greater than in the puna $\left(5.5 \%\right.$ of added ${ }^{15} \mathrm{~N}$ in the paramo against $1.5 \%$ in the puna at the end of the incubation). In the puna, the model simulates faster ${ }^{15} \mathrm{~N}$ mineralization and faster transfer through the compartments of microbial origin and less storage in the stable humus. 
Figure 4 Climatic correction, $f(T) f(\theta)$ in Equation (1), acting on the kinetic constants (Table 3) of the MOMOS-6 model. For time axis, day 0 is 13 November 1998.
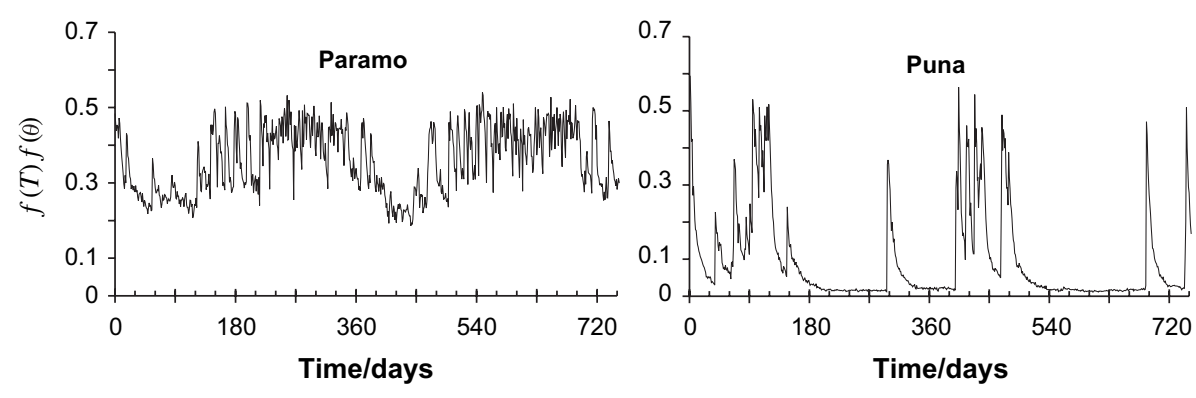

\section{Discussion}

\section{Microbial respiration and biomass}

At both sites, after the initial peak (about 10 days incubation), the values of the simulated metabolic quotient (Figure 5) were in the range of those measured by Anderson \& Domsch (1993) at $22^{\circ} \mathrm{C}$ in several forest soils sampled in early spring. The smallest values, near $20 \mathrm{mg}\left(\mathrm{CO}_{2}-\mathrm{C}\right) \mathrm{g}^{-1}$ (microbial-C) day ${ }^{-1}$, were in the range of the paramo values during the weak activity phases; the greatest values, at $75 \mathrm{mg}\left(\mathrm{CO}_{2}-\mathrm{C}\right) \mathrm{g}^{-1}$ (microbial-C) day ${ }^{-1}$, slightly exceeded the puna values during the wet periods $(10$ 65 , Figure 5). Sarmiento \& Bottner (2002) measured $q \mathrm{CO}_{2^{-}}{ }^{14} \mathrm{C}$ in a laboratory experiment in which ${ }^{14} \mathrm{C}$ labelled straw was incubated in a soil from the same paramo site. At 33 days, $q \mathrm{CO}_{2^{-}}{ }^{14} \mathrm{C}$ was $113 \mathrm{mg}\left(\mathrm{CO}_{2^{-}}{ }^{14} \mathrm{C}\right) \mathrm{g}^{-1}$ (microbial- ${ }^{14} \mathrm{C}$ ) day ${ }^{-1}$ and should correspond to the first initial peak (Figure 5) under these conditions. After 80 days, $q \mathrm{CO}_{2^{-}}{ }^{14} \mathrm{C}$ was $26 \mathrm{mg}$ $\left(\mathrm{CO}_{2^{-}}{ }^{14} \mathrm{C}\right) \mathrm{g}^{-1}$ (microbial- ${ }^{14} \mathrm{C}$ ) day ${ }^{-1}$, i.e. in the range $15-30 \mathrm{mg}$ $\left(\mathrm{CO}_{2^{-}}{ }^{14} \mathrm{C}\right) \mathrm{g}^{-1}$ (microbial- ${ }^{14} \mathrm{C}$ ) day ${ }^{-1}$ simulated by MOMOS-6 for this paramo experiment. Under field conditions in the same part of the Venezuelan paramo, Sarmiento (1995) found $q \mathrm{CO}_{2}$ values between 10 and $48 \mathrm{mg}\left(\mathrm{CO}_{2}-\mathrm{C}\right) \mathrm{g}^{-1}$ (microbial-C) $\mathrm{day}^{-1}$. The largest values were measured after incorporation of green manure.

At the end of this experiment the differences in microbial respiration result in smaller pseudo-equilibrium values of $\mathrm{MB}$ in the puna than in the paramo. Large $k_{\text {resp }}$ also leads to fast mineralization at the beginning of incubation and sharply reduces the time required to reach pseudo-equilibrium. After 6 months, the fraction of added ${ }^{14} \mathrm{C}$ mineralized in the puna was twice the fraction mineralized in the paramo (Figure 6). The fraction of inorganic- ${ }^{15} \mathrm{~N}$ produced in the puna was three times as large as that in the paramo (Figure 8). Despite the less favourable conditions, transformation processes are faster in the puna than in the paramo, because of the difference in microbial respiration.

\section{Microbial respiration and ${ }^{14} \mathrm{C}$ and ${ }^{15} \mathrm{~N}$ sequestration}

Given the identical $k_{\mathrm{VL}}$ and $k_{\mathrm{Vs}}$ values at the two sites, the smaller $k_{\text {resp }}$ value estimated for the paramo leads to a smaller respiration output and a larger size of the labelled microbialpool than in the puna. The microbial biomass- ${ }^{14} \mathrm{C}$ ranges from 3.5 to $1.5 \%$ of the added ${ }^{14} \mathrm{C}$ in the paramo between 3 and 24 months of incubation and ranges from 2.25 to $1.5 \%$ in the puna during the same incubation period. In the paramo, greater $\mathrm{MB}$ values lead to greater microbial mortality and larger values of HL than in the puna soil, notwithstanding the identical $k_{\mathrm{MB}}$. Whereas in the paramo the predicted $\mathrm{HL}-{ }^{14} \mathrm{C}$ decreases from $35 \%$ to $15 \%$ of the added ${ }^{14} \mathrm{C}$ between 3 and 24 months of incubation, it decreases from $25 \%$ to $15 \%$ in the puna during the same incubation period. In turn, the larger size of the HL pool leads to increased HL outputs towards the $\mathrm{MB}$ and towards HS (although $k_{\mathrm{HL}}$ and $k_{\mathrm{HLS}}$ are the same at the two sites). For the paramo, MOMOS- 6 predicted a larger ${ }^{14} \mathrm{C}$ and ${ }^{15} \mathrm{~N}$ storage in the stable HS compartment for a soil with a smaller $k_{\text {resp }}$ : after 2 years, $2 \%$ of added ${ }^{14} \mathrm{C}$ and $7.5 \%$ of added ${ }^{15} \mathrm{~N}$ are stored as stable $\mathrm{HS}$ in the paramo, whereas only $0.4 \%$ of added ${ }^{14} \mathrm{C}$ and $1.5 \%$ of added ${ }^{15} \mathrm{~N}$ are stored in HS in the puna (Figures 7 and 9).

The model adjustment reproduces the field data: although the weather was more favourable for mineralization, the total native
Figure 5 Metabolic quotient of the microbial biomass simulated by the MOMOS- 6 model. For time axis, day 0 is 13 November 1998.
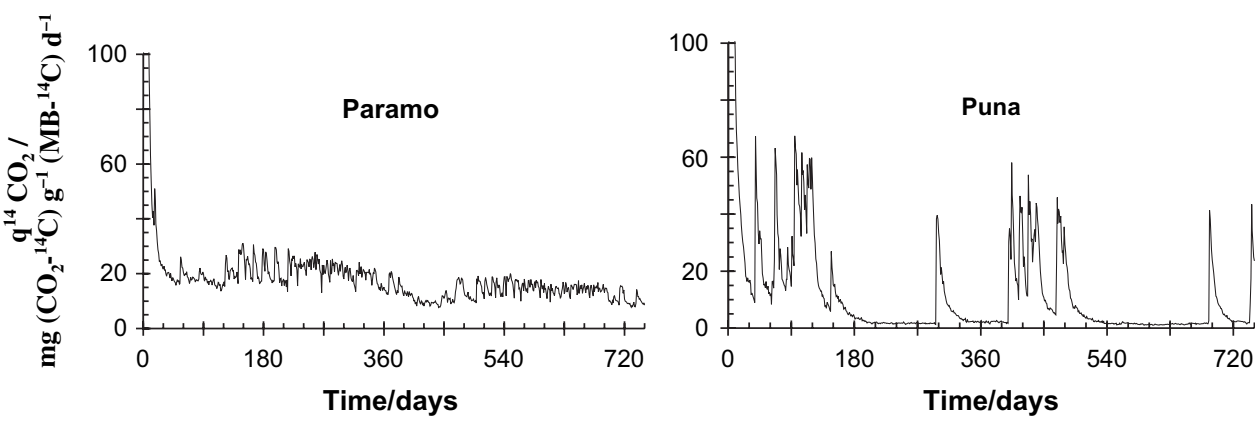

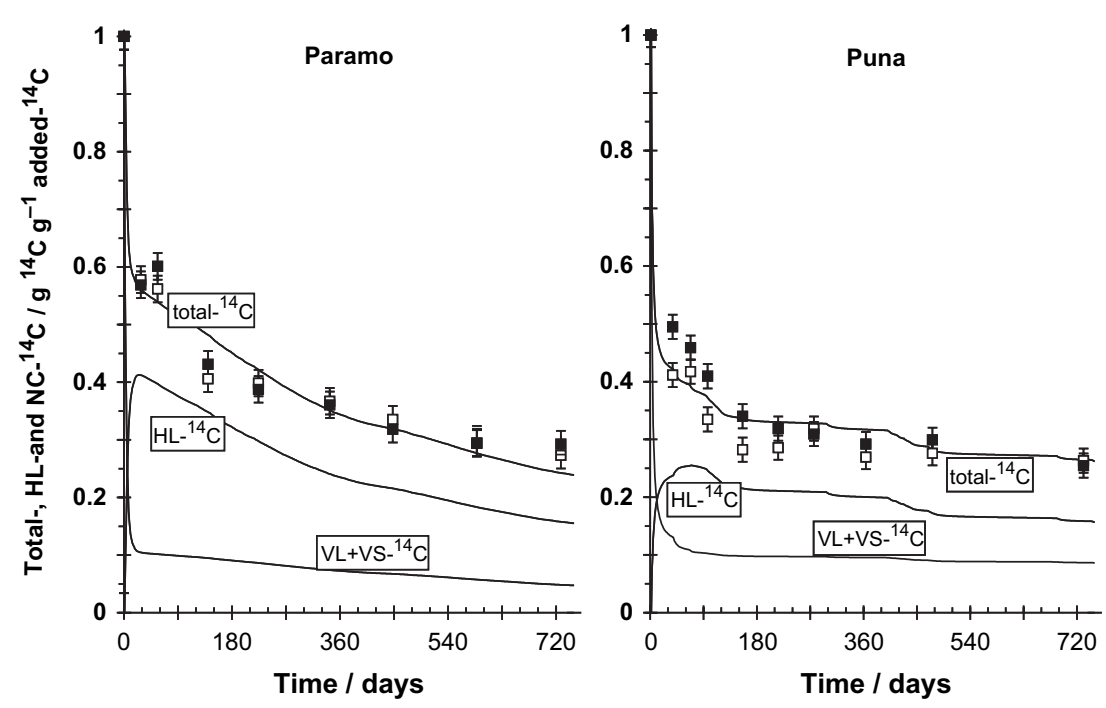

Figure 6 Time course of total-, HL- and (VL + VS) $-{ }^{14} \mathrm{C}$ in $\mathrm{g}{ }^{14} \mathrm{C} \mathrm{g} \mathrm{g}^{-1}$ initially added $-{ }^{14} \mathrm{C}$; lines $=$ MOMOS-6 predictions; $\square, \mathbf{\square}=$ measured total ${ }^{14} \mathrm{C}$ in the Young and Old fallow plots, respectively, with $95 \%$ confidence intervals. For time axis, day 0 is 13 November 1998. Abbreviations as in Figure 1. organic matter stored in the wet paramo soil $(\mathrm{C}=9 \%$, Table 2$)$ is about 18 times that stored in the dry puna $(\mathrm{C}=0.5 \%)$. Carbon and nitrogen lost by leaching cannot explain the difference between the two ecosystems, first because of the magnitude of the difference and secondly because the moisture regime is less favourable for leaching in the puna than in the paramo (Figure 3). The productivity of the two ecosystems modelled by the FAPROM model of Martineau \& Saugier (2006) cannot completely explain the large difference in organic matter content of the soils (Y. Martineau and B. Saugier, personal communication). Based on our tracer study (effectively excluding productivity as an experimental factor), the difference is explained by a weaker mineralization in the paramo than in the puna. In the paramo, the model predicts larger accumulation of transient compounds of microbial origin (MB and HL) and finally larger storage of stable humus (HS).
From the MOMOS-6 simulations, the only form of stable $\mathrm{C}$ to accumulate more in the dry puna than in the wet paramo is the compartment that contains undecomposed plant fragments (VS). As the $k_{\mathrm{VL}}$ and $k_{\mathrm{VS}}$ values are the same at the two sites, the predicted slower decomposition of the puna VS is due to the influence of the drier weather. The comparison of the output rates of the HS pool $\left(k_{\mathrm{HS}}=0.018\right.$ year $^{-1}$, half-life $T_{1 / 2}=38$ years) and of VS ( $k_{\mathrm{VS}}=1.095$ year $^{-1}, T_{1 / 2}=0.6$ years $)$, suggests that the stabilization of $\mathrm{C}$ is much greater in the paramo than in the puna.

\section{Microbial respiration and soil properties}

Fine mineral phases are generally identified as protecting the humus compounds (e.g. Kleber et al., 2005). Nevertheless, Müller \& Höper (2004), analysing 491 soils over a large range
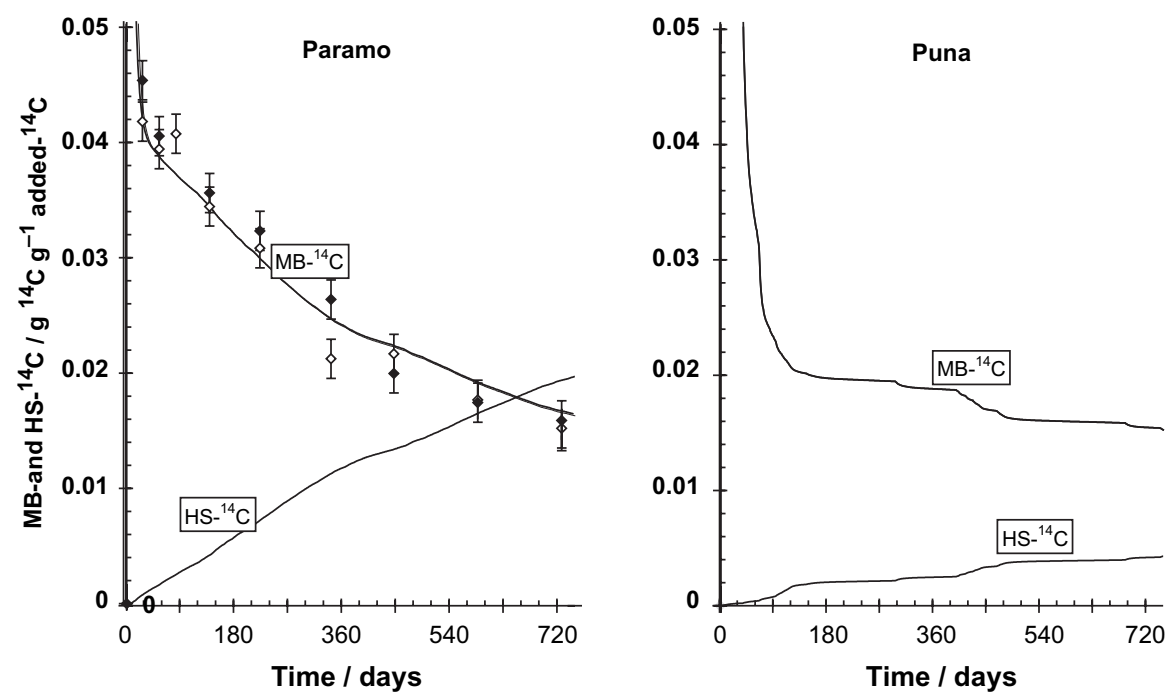

Figure 7 Time course of MB- and $\mathrm{HS}^{14}{ }^{14} \mathrm{C}$ in $\mathrm{g}{ }^{14} \mathrm{C} \mathrm{g} \mathrm{g}^{-1}$ initially added $-{ }^{14} \mathrm{C}$; lines $=$ MOMOS-6 predictions; $\diamond, \diamond=$ measured $\mathrm{MB}-{ }^{14} \mathrm{C}$ in the Young and Old fallow plots, respectively, with $95 \%$ confidence intervals (not measured in the puna). For time axis, day 0 is 13 November 1998. Abbreviations as in Figure 1. 
Figure 8 Time course of total-, HL (VL + VS)and inorganic- ${ }^{15} \mathrm{~N}$ in $\mathrm{g}^{15} \mathrm{~N} \mathrm{~g}^{-1}$ initially added $-{ }^{15} \mathrm{~N}$; lines $=$ MOMOS- 6 predictions; $\square$, $\mathbf{\square}=$ measured total ${ }^{15} \mathrm{~N}$ in the Young and Old fallow plots, respectively, with $95 \%$ confidence intervals. For time axis, day 0 is 13 November 1998. Abbreviations as in Figure 1.
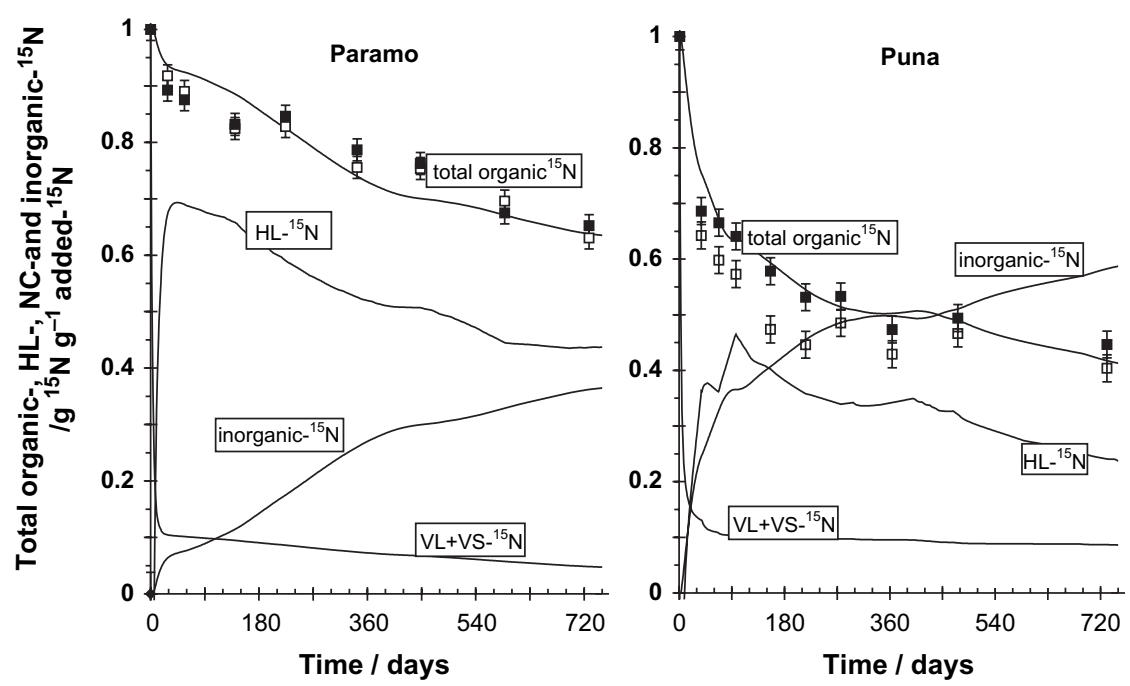

of climates, did not find significant relationships between clay content and dead organic matter. They observed a greater stabilizing effect of clays for microbial biomass than for humus, with a positive relationship between clay content and biomass and a negative relationship between clay content and $q \mathrm{CO}_{2}$, in accordance with what was found here.

Numerous labelling experiments have shown that fine soil texture generally reduces ${ }^{14} \mathrm{C}$ mineralization (e.g. Bo \& XinXiong, 1993). Total and microbial ${ }^{14} \mathrm{C}$ and ${ }^{15} \mathrm{~N}$ contents were greater in clay soils than in sandy loam soils (e.g. Ladd et al., 1995), and larger biophysical quotients (respired/residual ${ }^{14} \mathrm{C}$ ) were observed in soils with less clay (Saggar et al., 1999). Texture can affect decomposition indirectly by modifying the porosity and subsequent water and air circulation (Thomsen et al., 1999). According to Schjønning et al. (1999), oxygen diffusion becomes limiting for microbial activity when the airfilled pore volume becomes less than $0.2-0.3$ of the total pore volume for aerobic biochemical processes. From the SAHEL simulations, the volumetric moisture content in the labelled horizon of the paramo soil varies between 0.25 and 0.52 (Figure 3) for a field capacity (FC) of 0.52 (Table 1), inducing no major water stress for microorganisms $(f(T) f(\theta)$ between 0.25 and 0.5 , Figure 4 ), but the aerobic microbial activity was probably limited by lack of oxygen. In contrast, in the dry puna, the volumetric moisture content was always less than the field capacity $(\mathrm{FC}=0.35)$. Both dryness and low temperature halted the biological activity $(f(T) f(\theta) \cong 0$, Figure 4 ), but the puna is characterized by the absence of waterlogged episodes (Orsag, 1989) and microbial activity is probably never limited by lack of oxygen. This may explain the greater $k_{\text {resp }}$ (Table 3 ) and consequently the considerable mineralization when the moisture and temperature were not limiting.

Another explanation for the difference in the microbial activity is discussed in Bottner et al. (2006): in the paramo the exchangeable $\mathrm{Al}$ and free $\mathrm{Al}$ oxides $\left(25.5 \mathrm{~g} \mathrm{~kg}^{-1}\right)$ at $\mathrm{pH} 4.5$
Figure 9 Time course of MB- and HS- ${ }^{15} \mathrm{~N}$ in $\mathrm{g}$ ${ }^{15} \mathrm{~N} \mathrm{~g}^{-1}$ initially added $-{ }^{15} \mathrm{~N}$; lines = MOMOS- 6 predictions; $\diamond, \diamond=$ measured $\mathrm{MB}^{-15} \mathrm{~N}$ in the Young and Old fallow plots, respectively, with $95 \%$ confidence intervals (not measured in the puna). For time axis, day 0 is 13 November 1998. Abbreviations as in Figure 1.
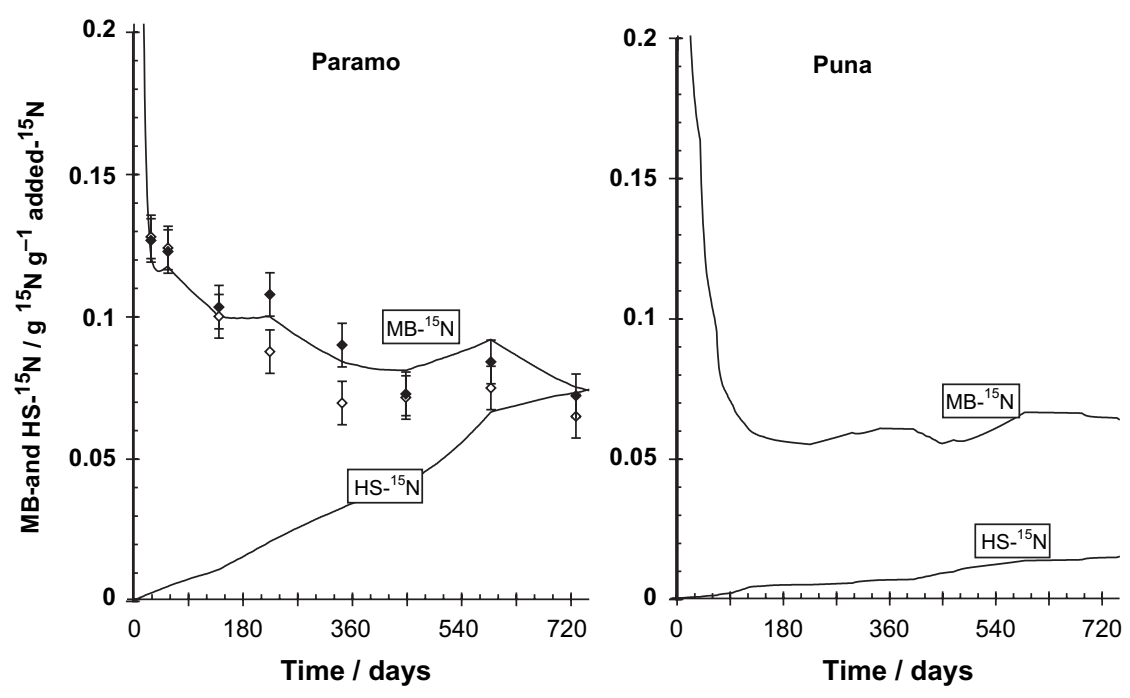
(Table 1) can inhibit microbial activity compared with the puna, where the $\mathrm{Al}$ values are negligible.

As shown above in the introduction section, soil texture is generally the only soil abiotic factor that is taken into account in decomposition models. Our analysis suggests that microbial respiration $\left(k_{\text {resp }}\right)$ is the only parameter that differs between the wet paramo and the dry puna. If texture is the explanatory factor (albeit direct or indirect), then the calibration result suggests the following interpolation of the respiration rate $k_{\text {resp }}$ of the decomposing organisms (acting on the microbial pool size):

$$
k_{\text {resp }}=0.127-0.0021 F \text { for } F<46 \% \text {, }
$$

where $F=$ the percentage of the $0-20 \mu \mathrm{m}$ fraction of soil particles. Equation (8) is a linear interpolation between $k_{\text {resp }}$ (Table $3 ; k_{\text {resp }}=0.084$ for the dry puna and 0.03 for the wet paramo) and $F$ (Table $1 ; F=20.8 \%$ for the puna and $46 \%$ for the paramo). It is based on only two pairs of data and so must be used carefully even if MOMOS- 6 was found less sensitive to parameter fluctuations than four other models (Pansu et al., 2004). A minimum value has to be chosen for $k_{\text {resp }}$ to avoid 0 or negative values when $F \geq 60 \%$.

\section{Conclusion}

As all the MOMOS-6 parameters are kinetic constants related to temperature and moisture, this model is particularly sensitive to weather influence. In the wet paramo, even during the dry period, the minimum soil water storage over the 2 years of the experiment was $0.25 \mathrm{~mm}$ water $\mathrm{mm}^{-1}$. Consequently, the transformation processes of organic matter, essentially controlled by a fairly constant temperature and moisture regime, were fairly uniform. The predicted metabolic quotient $\left(q \mathrm{CO}_{2}-{ }^{14} \mathrm{C}\right)$ is in the range of published values and validated by two complementary studies in the same paramo: $q \mathrm{CO}_{2^{-}}{ }^{14} \mathrm{C}$ from a laboratory incubation and $q \mathrm{CO}_{2}$ measurements in the field. In the dry puna, the processes were more seasonal and almost halted by the lack of water during the long dry winters and slowed down by the scarcity of water even during the wet season.

Similar values were found in the two sites for six of the seven MOMOS-6 kinetic constants that regulate transfers between the model compartments. Only the values of the respiration rate, $k_{\text {resp }}$, and of the equilibrium concentration of labelled microbial biomass at the steady state were specific to the site. In the paramo, $k_{\text {resp }}$ was found to be less than one-third of that in the puna. Consequently, $q \mathrm{CO}_{2^{-}}{ }^{14} \mathrm{C}$ varied over a much larger range in the puna than in the paramo. This resulted in faster measured and predicted ${ }^{14} \mathrm{C}$ and ${ }^{15} \mathrm{~N}$ mineralization in the puna than in the paramo, despite the long water-limited periods in the puna. The smaller $k_{\text {resp }}$ and $\mathrm{CO}_{2}$ output in the paramo increase the size of the microbial compartment and, through microbial mortality, increase the size of the labile microbial metabolites compartment (even with the same rate of microbial mortality in each site). In turn, this induces a larger output of labile microbial metabolites, both towards living microorganisms and towards the stable humus compartment (even at constant microbial ingestion rate and stabilization rate). After 2 years, the fraction of added ${ }^{14} \mathrm{C}$ and ${ }^{15} \mathrm{~N}$ stabilized in the stable humus compartment in the paramo was five times that in the puna. Obviously, the difference in microbial respiration is the crucial mechanism that explains the different behaviour of the two soils with respect to $\mathrm{C}$ and $\mathrm{N}$ storage. For the parameterization of the effect of soil texture, the linear interpolation between the values of respiration rate, $k_{\text {resp, }}$ and clay + silt percentage, enables us to use this modelling approach in other situations. To do so, data on the amount and quality (fibre content and $\mathrm{C}: \mathrm{N}$ ratios) of added organic matter, soil data (basal microbial biomass and texture), moisture content at field capacity and at wilting point (required for water balance calculations) and climatic data (temperature and rainfall) are required.

\section{Acknowledgements}

This work was supported by the INCO-DC programme of the European Union: TROPANDES No ERBIC18CT98-0263. We are grateful to A. Olivo and N. Marquez from ICAE, Mérida, Venezuela, R. Callisaya from IBTEN, La Paz, Bolivia, B. Buatois from CEFE-CNRS, Montpellier, France, for soil samplings and analysis, and to Professor T. Carballas, CSICIIAG, Santiago de Compostela, Spain, coordinator of the EU programme.

\section{References}

Anderson, T.H. \& Domsch, K.H. 1993. The metabolic quotient for $\mathrm{CO}_{2}\left(q \mathrm{CO}_{2}\right)$ as a specific activity parameter to assess the effect of environmental conditions such as $\mathrm{pH}$ on the microbial biomass of forests soil. Soil Biology and Biochemistry, 25, 393-395.

Andrén, O. \& Paustian, K. 1987. Barley straw decomposition in the field: a comparison of models. Ecology, 68, 1190-1200.

Bo, S. \& Xin-Xiong, L. 1993. Effects of soil texture and $\mathrm{CaCO}_{3}$ on turnover of organic material in Chao soils. Pedosphere, 3, 133-144.

Bosatta, E. \& Ågren, G.I. 1997. Theoretical analyses of soil texture effects on organic matter dynamics. Soil Biology and Biochemistry, 29, 1633-1638.

Bottner, P., Pansu, M., Sarmiento, L., Hervé, D., Callisaya-Bautista, R. \& Metselaar, K. 2006. Factors controlling decomposition of soil organic matter in the fallow systems of the high tropical Andes: a field simulation approach using ${ }^{14} \mathrm{C}$ and ${ }^{15} \mathrm{~N}$ labelled plant material. Soil Biology and Biochemistry, 38, 2162-2177.

Bottner, P. \& Warembourg, F. 1976. Method for simultaneous measurement of total and radioactive carbon in soils, soil extracts and plant materials. Plant and Soil, 45, 273-277. 
Franko, U., Oelschlägel, B. \& Schenk, S. 1995. Simulation of temperature, water and nitrogen dynamics using the model CANDY. Ecological Modelling, 81, 213-222.

Hansen, S., Jensen, H.E., Nielsen, N.E. \& Svendsen, H. 1991. Simulation of nitrogen dynamics and biomass production in winter wheat using the Danish simulation model DAISY. Fertilizer Research, 27, 245-259.

Hassink, J. \& Whitmore, A.P. 1997. A model of the physical protection of organic matter in soils. Soil Science Society of America Journal, 61, 131-139.

Hervé, D. 1994. Respuestas de los componentes de la fertilidad del suelo a la duración del descanso. In: Dinámicas Del Descanso de la Tierra En Los Andes (eds D. Hervé, D. Genin \& G. Rivière), pp. 155-169. Orstom-Ibta, La Paz.

Jenkinson, D.S. 1990. The turnover of organic carbon and nitrogen in soil. Philosophical Transactions of the Royal Society London, Biological Sciences, 329, 361-368.

Jenkinson, D.S. \& Powlson, D.S. 1976. The effects of biocidal treatments on metabolism in soil. V. A method for measuring soil biomass. Soil Biology and Biochemistry, 8, 209-213.

Kätterer, T., Reichstein, M., Andrén, O. \& Lomander, A. 1998. Temperature dependence of organic matter decomposition: a critical review using literature data analyzed with different models. Biology and Fertility of Soils, 27, 258-262.

Kleber, M., Mikutta, R., Torn, M.S. \& Jahn, R. 2005. Poorly crystalline mineral phases protect organic matter in acid subsoil horizons. European Journal of Soil Science, 56, 717-725.

Ladd, J.N., Amato, M., Grace, P.R. \& van Veen, J.A. 1995. Simulation of ${ }^{14} \mathrm{C}$ turnover through the microbial biomass in soils incubated with ${ }^{14} \mathrm{C}$-labelled plant residues. Soil Biology and Biochemistry, 27, 777-783.

Martineau, Y. \& Saugier, B. 2006. Comportement contre-intuitif d'un modèle mécaniste de succession végétale. Comptes Rendus de l'Académie Des Sciences de Paris, Biologie Ecologie, 329, 21-30.

Molina, J.A.E., Nicolardot, B. \& Cheng, H.H. 1998. Influence of clay content and time on soil organic matter turnover and stabilization. In: 16th World Congress of Soil Science, Montpellier (eds IUSS), p. 8. IRIC, Wageningen, The Netherlands.

Müller, T. \& Höper, H. 2004. Soil organic matter turnover as a function of the soil clay content: consequences for model applications. Soil Biology and Biochemistry, 36, 877-888.

Orsag, V. 1989. Características del régimen aéreo de un aridosol del altiplano central de Bolivia. Ecología En Bolivia, 13, 11-21.

Pansu, M., Bottner, P., Sarmiento, L. \& Metselaar, K. 2004. Comparison of five soil organic matter decomposition models using data from a ${ }^{14} \mathrm{C}$ and ${ }^{15} \mathrm{~N}$ labelling field experiment. Global Biogeochemical Cycles, 18, GB4022.

Parton, W.J., Schimel, D.S., Cole, C.V. \& Ojima, D.S. 1987. Analysis of factors controlling soil organic matter levels in Great Plains grasslands. Soil Science Society of America Journal, 51, 1173-1179.

Penning de Vries, F.W.T., Jansen, D.M., ten Berge, H.F.M. \& Bakema, A. 1989. Simulation of Ecophysiological Processes of Growth in Several Annual Crops. Pudoc, Wageningen.

Saggar, S., Parshotam, A., Hedley, C. \& Salt, G. 1999. ${ }^{14}$ C-labelled glucose turnover in New Zealand soils. Soil Biology and Biochemistry, 31, 2025-2037.

Saggar, S., Parshotam, A., Sparling, G.P., Feltham, C.W. \& Hart, P.B.S. 1996. ${ }^{14} \mathrm{C}$-labelled ryegrass turnover and residence times in soils varying in clay content and mineralogy. Soil Biology and Biochemistry, 28, 1677-1686.

Sarmiento, L. 1995. Restauration de la fertilité dans un système agricole à jachère longue des hautes Andes du Venezuela. Thèse de Doctorat. Université de Paris XI, Paris.

Sarmiento, L. \& Bottner, P. 2002. Carbon and nitrogen dynamics in two soils with different fallow times in the high tropical Andes: indications for fertility restoration. Applied Soil Ecology, 19, 79-89.

Schimel, J.P. \& Weintraub, M.N. 2003. The implications of exoenzyme activity on microbial carbon and nitrogen limitation in soil: a theoretical model. Soil Biology and Biochemistry, 35, 549-563.

Schjønning, P., Thomsen, I.K., Møberg, J.P., de Jonge, H., Kristensen, K. \& Christensen, B.T. 1999. Turnover of organic matter in differently textured soils. I. Physical characteristics of structurally disturbed and intact soils. Geoderma, 89, 177-198.

Thomsen, I.K., Schjønning, P., Jensen, B., Kristensen, K. \& Christensen, B.T. 1999. Turnover of organic matter in differently textured soils. II. Microbial activity as influenced by soil water regimes. Geoderma, 89, 199-218.

Thuriès, L., Pansu, M., Larré-Larrouy, M.C. \& Feller, C. 2002. Biochemical composition and mineralization kinetics of organic inputs in a sandy soil. Soil Biology and Biochemistry, 34, 239-250.

Van Soest, P.J., Robertson, J.B. \& Lewis, B.A. 1991. Symposium: carbohydrate methodology, metabolism, and nutritional implications in dairy cattle. Journal of Dairy Science, 74, 3583-3597.

Van Veen, J.A., Ladd, J.N. \& Amato, M. 1985. Turnover of carbon and nitrogen through the microbial biomass in a sandy loam and a clay soil incubated with $\left[{ }^{14} \mathrm{C}(\mathrm{U})\right]$ glucose and $\left[{ }^{15} \mathrm{~N}\right]\left(\mathrm{NH}_{4}\right)_{2} \mathrm{SO}_{4}$ under different moisture regimes. Soil Biology and Biochemistry, 17, 747-756.

Verberne, E.L., Hassink, J., de Willigen, P., Groot, J.J.R. \& van Veen, J.A. 1990. Modelling organic matter dynamics in different soils. Netherlands Journal of Agricultural Science, 38, 221-238. 